\title{
EL CONTROL DE CONVENCIONALIDAD \\ A TRAVÉS DEL CONTROL CONCRETO DE CONSTITUCIONALIDAD EN EL ECUADOR ${ }^{1}$
}

\author{
RODRIGO DURANGO ${ }^{2}$
}

\section{RESUMEN}

La Corte Interamericana de Derechos Humanos ha sido prolífica al buscar mecanismos de mayor protección de los derechos humanos en el continente. Uno de ellos es el denominado control de convencionalidad, que pretende cohesionar el ordenamiento jurídico interno con la Convención Americana sobre Derechos Humanos, con el fin de que las normas jurídicas internas no se contrapongan a este instrumento internacional. Este mecanismo jurídico no ha estado libre de críticas. Es necesario determinar cuál es el instrumento procesal que poseen los jueces ecuatorianos para realizar este control, de manera que sea consistente con el ordenamiento jurídico ecuatoriano. El trabajo pretende demostrar que es a través del control concreto de constitucionalidad, el mecanismo procesal por medio del cual los jueces ecuatorianos deben realizar el control de convencionalidad.

\section{PALABRAS CLAVE}

Control de convencionalidad, control concreto de constitucionalidad, Derechos Humanos.

\footnotetext{
1 Artículo entregado por el autor el 6 de agosto de 2016 y aprobado el 4 de diciembre de 2016.

2 Abogado de la Procuraduría General del Estado.
} 


\begin{abstract}
The Interamerican Court of Human Rights has been prolific to seek mechanisms for greater protection of human rights on the continent. One of them is called conventionality control, which aims to cohere domestic law with the American Convention on Human Rights, so that the domestic legal provisions do not conflict with this international instrument. This legal mechanism has not been free of criticism. In Ecuador it is necessary to determine the procedural instrument that judges have to perform the conventionality control that is consistent with the Ecuadorian legal system. This paper aims to demonstrate that concrete control of constitutionality is the procedural mechanism by which the Ecuadorian judges must perform control of conventionality.
\end{abstract}

\title{
KEY WORDS
}

Conventionality Control, Specific Control of Constitutionality, Human Rights. 


\section{INTRODUCCIÓN}

Los derechos humanos fueron reconocidos como esos valores supremos que deben respetarse en todo momento y lugar, a raíz de las revoluciones francesa y estadounidense en el siglo dieciocho. Posteriormente, se positivaron en las constituciones de varias naciones que procuraban un nuevo orden.

Luego de la Segunda Guerra Mundial, surgió un nuevo orden mundial con la Organización de Naciones Unidas y la aprobación, más tarde, de varios tratados internacionales de derechos humanos; se dio la internacionalización de los derechos fundamentales, que debían respetarse independientemente de la nacionalidad de los individuos, y se reconocía al ser humano como sujeto del Derecho internacional de los derechos humanos. Además, acompaña a este fenómeno, aquel denominado como universalización del derecho constitucional, el cual se construye sobre valores comunes como la democracia, los derechos humanos, el estado de derecho, la soberanía popular, los poderes limitados por el derecho, la constitucionalización de los derechos individuales con los de corte social, el control de constitucionalidad y la protección judicial de los derechos.

Este nuevo constitucionalismo también reconoce a las fuentes del Derecho internacional, lo que incluye a las interpretaciones judiciales que realizan dichos organismos internacionales y a la constitucionalización de estos tratados.

La Corte Interamericana de Derechos Humanos (en adelante "Corte" o "Corte Interamericana") ha sido prolífica al buscar mecanismos de mayor protección de los derechos humanos en el continente. Uno de ellos es el denominado control de 
convencionalidad, que será abordado con mayor detalle en la primera parte de esta investigación. Dicho mecanismo pretende cohesionar el ordenamiento jurídico interno con la Convención Americana sobre Derechos Humanos (en adelante "Convención" o "Convención Americana"), con el fin de que las normas jurídicas internas no se contrapongan a este instrumento internacional. Evidentemente, esta doctrina de la Corte no ha sido ajena a las críticas de algunos autores, como será abordado en el trabajo que aquí presento. Desde luego, el uso inadecuado de este mecanismo podría terminar por deslegitimarlo.

La presente investigación procura entregar un análisis de este control desde la perspectiva de la jurisprudencia de la Corte Interamericana, la doctrina que se ha diseñado en este sentido $\mathrm{y}$, finalmente, revisar las críticas que existen contra el control de convencionalidad. A continuación, abordaremos la naturaleza jurídica del control concreto de constitucionalidad en el Ecuador, a la luz de las normas constitucionales pertinentes y la jurisprudencia de la Corte Constitucional del Ecuador, a fin de demostrar que este mecanismo de control constitucional en el país es el idóneo para ejercer el control de convencionalidad, desde la perspectiva del Derecho constitucional ecuatoriano y dentro de las limitaciones que exige la Constitución de la República. Finalmente, se establecerá la existencia de un diálogo jurisprudencial entre los tribunales internacionales de derechos humanos y las cortes constitucionales latinoamericanas -en el caso que nos preocupa, la Corte ecuatoriana - para, de tal modo, determinar la manera en que se ejercerá este control por parte de los jueces ecuatorianos. 


\title{
ALCANCE Y CONTENIDO DEL CONTROL DE CONVENCIONALIDAD
}

\section{La doble obligación de los Estados de respetar y garantizar los derechos humanos}

Es conveniente que, antes de explorar la naturaleza jurídica del control de convencionalidad, este ensayo analice las características de las obligaciones de los Estados en el marco del Derecho internacional de los derechos humanos, de tal suerte que el lector conozca el antecedente de la llamada "doctrina del control de convencionalidad". Pues bien, el artículo 1.1 de la Convención Americana sobre Derechos Humanos (en adelante "Convención" o "Convención Americana") dispone:

\begin{abstract}
Los Estados partes de esta Convención se comprometen a respetar los derechos y libertades reconocidos en ella y a garantizar su libre y pleno ejercicio a toda persona que esté sujeta a su jurisdicción, sin discriminación alguna por motivos de raza, color, sexo, idioma, religión, opiniones políticas o de cualquier otra índole, origen nacional o social, posición económica, nacimiento o cualquier otra condición social.
\end{abstract}

Esta disposición reconoce lo que ha sido denominado como el binomio "respetar y proteger", o también llamado "respetar y garantizar (respect/ensure respect)". Con relación a la primera obligación, la de respetar, la Corte Interamericana sostiene que

la protección a los derechos humanos, en especial los derechos civiles y políticos recogidos en la Convención, parte de la afirmación de la existencia de ciertos atributos inviolables de la persona humana 
que no pueden ser legítimamente menoscabados por el ejercicio del poder público. Se trata de esferas individuales que el Estado no puede vulnerar o en las que sólo puede penetrar limitadamente. Así, en la protección a los derechos humanos, está necesariamente comprendida la noción de la restricción al ejercicio del poder estatal (Corte IDH 1986 párr. 21).

Por lo tanto, el ejercicio de la actividad estatal o del poder público encuentra sus límites en el respeto a los derechos humanos. El Estado debe abstenerse de realizar actos que vulneren estos derechos y si es necesario interferir en esta esfera, solo puede hacerlo de forma muy restringida y limitada, de conformidad con lo establecido en los instrumentos internacionales o las constituciones respectivas.

La obligación de garantizar el libre y pleno ejercicio de los derechos reconocidos en la Convención también ha sido objeto de análisis por parte de la jurisprudencia de la Corte. La mencionada obligación se relaciona con el deber de cada Estado de organizar su aparato gubernamental, de manera que asegure jurídicamente el libre y pleno ejercicio de los derechos humanos. Se requiere, entonces, no sólo que exista un orden jurídico que realice esta obligación internacional; sino, además, una conducta estatal que asegure en la realidad la existencia de esta garantía. En consecuencia, los Estados partes de la Convención Americana deben prevenir, investigar, sancionar y reparar adecuadamente las violaciones a estos derechos que ocurran en sus jurisdicciones (Corte IDH 1988 párrs. 164 - 167). 
El Pacto Internacional de Derechos Civiles y Políticos (en adelante "PIDCP") contiene una norma similar en el párrafo 1 de su segundo artículo:

\begin{abstract}
Art. 2.1. Cada uno de los Estados Partes en el presente Pacto se compromete a respetar y a garantizar a todos los individuos que se encuentren en su territorio y estén sujetos a su jurisdicción los derechos reconocidos en el presente Pacto, sin distinción alguna de raza, color, sexo, idioma, religión, opinión política o de otra índole, origen nacional o social, posición económica, nacimiento o cualquier otra condición social.
\end{abstract}

El Comité de Naciones Unidas de Derechos Económicos, Sociales y Culturales ha indicado que, como producto de esta norma, los Estados tienen la obligación de respetar, proteger y realizar los derechos humanos. En efecto, la obligación de respetar exige que los Estados partes se abstengan de interferir en el disfrute de los derechos. Por ejemplo, el derecho a la educación se viola si el Estado parte niega a niñas embarazadas la permanencia en el sistema escolar. La obligación de proteger exige que el Estado parte prevenga violaciones a los derechos humanos por parte de terceros. Por ejemplo, que el Estado no garantice que los sistemas de salud cumplan con normas mínimas en materia de salud sexual y reproductiva puede considerarse una violación al derecho a la salud. La obligación de realizar exige que el Estado parte promueva la adopción de medidas legislativas, administrativas, presupuestales y judiciales, entre otras, que resulten necesarias para alcanzar la efectiva realización de los derechos. Incluso, en el ámbito del Derecho internacional humanitario, son fundamentales las consecuencias derivadas del artículo 1 de los Convenios de Ginebra y del artículo 1.1 del Protocolo Adicional I de 1977, 
por los cuales las Altas Partes Contratantes se comprometen a "respetar y hacer respetar en todas las circunstancias los tratados internacionales humanitarios".

Por su parte, la Convención Europea sobre Derechos Humanos establece en su primer artículo la obligación de asegurar -shall secure- los derechos fundamentales para todos los Estados que forman parte de este tratado internacional. Igualmente, la Convención sobre los Derechos del Niño señala en su artículo 2.1 la obligación para los Estados partes de respetar y asegurar los derechos del niño; además de comprometerlos a respetar y hacer respetar las normas y reglas del Derecho humanitario, de conformidad con el artículo 38.1 de este convenio. Adicionalmente, la Corte Internacional de Justicia sostuvo expresamente la obligación de hacer respetar el Derecho humanitario al condenar a los Estados Unidos por violaciones al artículo 3 común a los Cuatro Convenios de Ginebra en Nicaragua, y señalar que el primero

tiene[n] la obligación, en términos del artículo 1 de los cuatro Convenios de Ginebra de respetar y también hacer respetar estos Convenios, pues tal obligación no deriva sólo de los propios Convenios, sino también de los principios generales del derecho humanitario a los cuales los Convenios simplemente dan expresión concreta" (Corte Internacional de Justicia 129, 130, $218,220,255,256)$.

En consecuencia,

las obligaciones de los Estados partes abarcan incondicionalmente el deber de asegurar el 


\begin{abstract}
cumplimiento de las disposiciones de aquellos tratados por todos sus órganos y agentes así como por todas las personas sujetas a su jurisdicción, y el deber de asegurar que sus disposiciones sean respetadas por todos, en particular por los demás Estados parte. Tales deberes se sitúan claramente en el plano de las obligaciones erga omnes (Ibid.).
\end{abstract}

\title{
Origen, naturaleza jurídica, concepto y efectos del control de convencionalidad
}

El preámbulo de la Convención Americana señala que la jurisdicción de los órganos del Sistema Interamericano de Derechos Humanos es "coadyuvante o complementaria" de las jurisdicciones nacionales de los Estados partes. Esta calificación realizada por la Convención revela que debe existir una interacción constante entre las legislaciones doméstica e internacional, en particular en lo que a protección de derechos fundamentales se refiere. Más aún, si la mayoría de constituciones latinoamericanas reconocen un valor preponderante a las normas del Derecho internacional de los derechos humanos, dentro de lo que se ha denominado el bloque de constitucionalidad; es decir, le otorgan preponderancia a la justicia internacional en esta materia. Por ello, esta interacción busca asegurar, en la mayor medida posible, el pleno disfrute de los derechos humanos en las jurisdicciones de los Estados partes de la Convención.

La ratificación de un tratado internacional, por parte de un Estado, trae consigo algunas consecuencias jurídicas, y dicho Estado debe asumir algunas obligaciones para asegurar el cumplimiento de esas disposiciones, puesto que el instrumento internacional ratificado entra a formar parte del ordenamiento jurídico del país 
en cuestión. Bajo esta perspectiva, el artículo 2 de la Convención Americana dispone:

Artículo 2. Deber de adoptar disposiciones de Derecho interno.- Si el ejercicio de los derechos y libertades mencionados en el artículo 1 no estuviere ya garantizado por disposiciones legislativas o de otro carácter, los Estados Partes se comprometen a adoptar, con arreglo a sus procedimientos constitucionales y a las disposiciones de esta Convención, las medidas legislativas o de otro carácter que fueren necesarias para hacer efectivos tales derechos y libertades.

El principio descrito implica que los Estados tienen la obligación general de adecuar su derecho interno a las disposiciones de la Convención para garantizar los derechos en ella consagrados, lo cual conlleva que dichas medidas de adecuación deban ser efectivas (principio effet utile) (Corte IDH 2006a párr. 171).

En el Derecho internacional existe una norma consuetudinaria universalmente aceptada que implica que si un Estado ratifica un tratado internacional de derechos humanos, debe modificar su derecho interno, con el fin de dar cabal cumplimiento a las disposiciones de dicho tratado (Corte IDH 2004a párr. 205). Consecuentemente, estas modificaciones deben implicar dos claras medidas a ser adoptadas por los Estados en las circunstancias descritas: primera, los Estados deben suprimir cualquier tipo de norma o práctica que suponga violación a las disposiciones de la Convención Americana, que desconozcan los derechos en ella consagrados u obstaculicen su ejercicio; y segunda, promulgar normas y desarrollar prácticas que conlleven la efectiva garantía de los derechos en mención (Corte IDH 2006a párr. 172). 
Es en este contexto, al tomar como punto de partida la obligación convencional de adoptar disposiciones de derecho interno, y desde la óptica que se ha indicado, se considera que el control de convencionalidad es consecuencia directa del deber de los Estados de tomar todas las medidas necesarias para que los tratados internacionales que han ratificado se cumplan cabalmente, pues no solo tienen la obligación de respetar, sino también la de garantizar los derechos humanos (CARBONELL 69).

Adicionalmente, la doctrina del control de convencionalidad encuentra sustento en el artículo 26 de la Convención de Viena sobre el Derecho de los Tratados, el cual dispone que "todo tratado en vigor obliga a las partes y debe ser cumplido por ellas de buena fe"; y, además, en el artículo 27 del mismo instrumento, al disponer que "una parte no podrá invocar las disposiciones de su derecho interno como justificación del incumplimiento de un tratado". Por estas razones, los Estados deben tomar todas las medidas jurídicas necesarias, dentro de su ordenamiento jurídico, para cumplir con sus obligaciones internacionales en materia de derechos humanos, y, desde este punto de vista, cobra relevancia el llamado control de convencionalidad.

Esta doctrina ha sido acuñada por la Corte Interamericana dentro de su jurisprudencia, aunque hay autores que la han criticado fuertemente, lo cual será revisado más adelante. Sergio García Ramírez, ex juez de la Corte Interamericana, en su voto concurrente dentro del caso Myrna Mack Chang contra Guatemala fue quien esbozó este concepto por primera vez dentro del Sistema Interamericano de Protección de Derechos Humanos, de la siguiente forma: 
No es posible seccionar internacionalmente al Estado, obligar ante la Corte sólo a uno o algunos de sus órganos, entregar a éstos la representación del Estado en el juicio — sin que esa representación repercuta sobre el Estado en su conjunto-y sustraer a otros de este régimen convencional de responsabilidad, dejando sus actuaciones fuera del "control de convencionalidad" que trae consigo la jurisdicción de la Corte Internacional (Corte IDH 2003).

Posteriormente, el mismo doctor García, dentro del caso Tibi contra el Ecuador, profundiza un poco más sobre el tema en otro voto concurrente razonado, al ponderar que la actividad de la Corte Interamericana

(...) se asemeja a la que realizan los tribunales constitucionales. Éstos examinan los actos impugnados — disposiciones de alcance general — a la luz de las normas, los principios y los valores de las leyes fundamentales. La Corte Interamericana, por su parte, analiza los actos que llegan a su conocimiento en relación con normas, principios y valores de los tratados en los que funda su competencia contenciosa. Dicho de otra manera, si los tribunales constitucionales controlan la "constitucionalidad", el tribunal internacional de derechos humanos resuelve acerca de la "convencionalidad" de esos actos. A través del control de constitucionalidad, los órganos internos procuran conformar la actividad del poder público - y, eventualmente, de otros agentes socialesal orden que entraña el Estado de derecho en una sociedad democrática. El tribunal interamericano, por 
su parte, pretende conformar esa actividad al orden internacional acogido en la Convención fundadora de la jurisdicción interamericana y aceptado por los Estados parte en ejercicio de su soberanía (Corte IDH 2004b párr. 3).

Sin embargo, no es sino hasta la sentencia, dictada dentro del caso Almonacid Arellano contra Chile, cuando la Corte Interamericana aborda el tema de forma directa en su jurisprudencia y ya no simplemente a través de estos votos razonados y concurrentes; es decir, existen mandatos jurisprudenciales expresos dirigidos a los Estados responsables de violaciones a los derechos humanos. Así, en el caso Almonacid, la Corte ponderó:

La Corte es consciente que los jueces y tribunales internos están sujetos al imperio de la ley y, por ello, están obligados a aplicar las disposiciones vigentes en el ordenamiento jurídico. Pero cuando un Estado ha ratificado un tratado internacional como la Convención Americana, sus jueces, como parte del aparato del Estado, también están sometidos a ella, lo que obliga a velar por que los efectos de las disposiciones de la Convención no se vean mermados por la aplicación de leyes contrarias a su objeto y fin, y que desde un inicio carecen de efectos jurídicos. En otras palabras, el Poder Judicial debe ejercer una especie de "control de convencionalidad" entre las normas jurídicas internas que aplican en los casos concretos y la Convención Americana sobre Derechos Humanos. En esa tarea, el Poder Judicial debe tener en cuenta no solamente el tratado, sino también la interpretación que del mismo ha hecho la Corte 
Interamericana, intérprete último de la Convención

Americana (Corte IDH 2006b párr. 124).

Luego, la Corte amplió esta noción al señalar que dicho control debía ser efectuado de oficio por los jueces correspondientes, en el marco de sus respectivas competencias y regulaciones procesales; empero, no debía ejercerse siempre sin considerar otros presupuestos formales y materiales de admisibilidad y procedencia (Corte IDH 2006c párr. 128). Incluso, el juez Sergio García Ramírez ha ido más allá, al afirmar que este control debe hacerse también con respecto al resto de instrumentos internacionales que forman parte del corpus juris interamericano y la interpretación que de ellos haya hecho la Corte Interamericana al respecto (Id. párr. 3). A pesar de que no es el propósito de este trabajo el revisar todos los casos en los cuales la Corte Interamericana ha hecho referencia al control de convencionalidad, conviene destacar que la Corte ha reiterado en su jurisprudencia esta obligación de los jueces. ${ }^{3}$

Según lo expresado en la jurisprudencia citada, es posible distinguir el control de convencionalidad desde dos ángulos: el

Ver Corte IDH, caso La Cantuta vs. Perú, fondo, reparaciones y costas, sentencia de 29 de noviembre de 2006, serie C, N. ${ }^{\circ}$ 162, párr. 173. Corte IDH, caso Boyce y otros vs. Barbados, excepción preliminar, fondo, reparaciones y costas, sentencia de 20 de noviembre de 2007, serie C, N. ${ }^{\circ} 169$, párr. 78. Corte IDH, caso Heliodoro Portugal vs. Panamá, excepciones preliminares, fondo, reparaciones y costas, sentencia de 12 de agosto de 2008, serie C, N. ${ }^{\circ} 186$, párr. 180. Corte IDH, caso Radilla Pacheco vs. México, excepciones preliminares, fondo, reparaciones y costas, sentencia de 23 de noviembre de 2009, serie C, N. ${ }^{\circ}$ 209, párr. 339. Corte IDH, caso Cabrera García y Montiel Flores vs. México, sentencia de excepción preliminar, fondo, reparaciones y costas, 26 de noviembre de 2010, serie C, N. ${ }^{\circ} 220$, párr. 225. Corte IDH, caso Gelman vs. Uruguay, fondo y reparaciones, sentencia de 24 de febrero de 2011, serie C, N. ${ }^{\circ}$ 221, párr. 239. 
nacional y el internacional. El primero es el relativo a la obligación de los jueces nacionales de contrastar las normas jurídicas de derecho interno que son aplicadas a un caso concreto, con respecto a su adecuación a las disposiciones de la Convención Americana. El segundo tiene relación con la protección de los derechos humanos consagrados en la Convención, y la facultad de la Corte para determinar si un acto o norma emanado del poder estatal es compatible con dicho instrumento internacional; y, si es así, ordenar su derogación o reforma, según corresponda. Lo mismo ocurre si la Corte encuentra que el Estado no ha adoptado disposiciones de derecho interno con el fin de adecuar su ordenamiento jurídico a las disposiciones de la Convención, en cuyo caso ordenará que se tomen las medidas legislativas pertinentes. En conclusión, existe un deslinde conceptual del control de convencionalidad bajo estas dos perspectivas, por medio de las cuales, tanto en sede nacional como internacional, se debe efectuar una fiscalización para que las normas jurídicas internas no se opongan a las normas de la Convención Americana (BAZÁn 2012a 24).

Existen autores que han encontrado, en el desarrollo de esta doctrina a través de la jurisprudencia de la Corte, cuatro etapas con respecto a los sujetos que deben realizar este control. En la primera etapa, la Corte señaló que el control de convencionalidad debe ser realizado por el Poder Judicial. La segunda fase habla de los órganos del Poder Judicial. Posteriormente, la jurisprudencia de la Corte menciona a los jueces y los órganos administradores de justicia en todos los niveles. Finalmente, establece que este control recae en todas las autoridades públicas y no solo en la Función Judicial (FERRER 390-391; BAZÁN 2012b 18). Consecuentemente, la Corte Interamericana ha procurado reforzar esta teoría en sus fallos, en clara aplicación del principio pro homine, al buscar 
que se amplíen los sujetos encargados de este control; además de reiterar el deber de los Estados de cumplir sus compromisos internacionales, al margen de las disposiciones de su derecho interno.

En cuanto al alcance del control de convencionalidad, si bien la Corte deja en claro la obligación de todas las autoridades públicas de realizar este control con respecto a las normas jurídicas que forman parte del ordenamiento jurídico de un país, cabe formularse la interrogante de si este control también abarca a las Constituciones de cada uno los Estados. En este orden de ideas, la Corte Interamericana ha indicado que

siempre que un convenio internacional se refiera a "leyes internas" sin calificar en forma alguna esa expresión o sin que de su contexto resulte un sentido más restringido, la referencia es para toda la legislación nacional y para todas las normas jurídicas de cualquier naturaleza, incluyendo disposiciones constitucionales (Corte IDH 1984 párr. 14).

Dentro del caso llamado La última tentación de Cristo contra Chile, la Corte ejerció este control de convencionalidad sobre normas constitucionales de ese Estado. Dicho tribunal encontró que el numeral 12 del artículo 19 de la Constitución chilena estaba en contraposición con normas de la Convención Americana, toda vez que establecía la censura previa en la producción cinematográfica, lo que violaba el artículo 13 de la Convención Americana, relativo a la libertad de expresión y pensamiento (Corte IDH 2001). Por este motivo, la Corte Interamericana estableció la responsabilidad internacional de Chile y ordenó que modificara su ordenamiento jurídico interno mediante la supresión 
de la censura previa (Id.punto resolutivo 4). En definitiva, la Corte no sólo efectuó un control de convencionalidad con respecto a la Constitución chilena, sino que le ordenó al Estado que la reforme para que sea compatible con la Convención.

Por otra parte, algunos autores han distinguido ciertos grados de intensidad en el ejercicio de este control. Incluso, la Corte Suprema de Justicia de México ha diseñado un esquema con el fin de que los jueces conozcan el modo de efectuar este control. Así, la Corte Suprema mexicana ha señalado los siguientes pasos para este cometido (FERRER 386): El primer paso - señala el Tribunal Supremo mexicano- es la aplicación de la interpretación conforme, en el sentido de que los jueces deben interpretar el ordenamiento jurídico a la luz de la Constitución y los instrumentos internacionales de derechos humanos, para lo cual debe observar el principio pro homine y proporcionar la interpretación que mejor proteja los derechos de las personas. El siguiente paso tiene relación con el principio de presunción de constitucionalidad de la norma, pues en el caso de que existan múltiples interpretaciones jurídicamente posibles, el juez debe preferir aquella que hace que la ley se encuentre acorde con los derechos humanos reconocidos en la Constitución y en los tratados internacionales en esa materia. Finalmente, el máximo tribunal de justicia mexicano también identifica una tercera y última etapa en el proceso de control de convencionalidad, que es la inaplicación de la ley cuando las alternativas anteriores no sean posibles. 


\section{Algunas críticas a la doctrina del control de convencionalidad}

Hemos analizado la naturaleza jurídica del control de convencionalidad, sus características y efectos, según la jurisprudencia emitida por la Corte Interamericana, y con una breve referencia a la jurisprudencia de la República de México. No obstante, este desarrollo doctrinal, por llamarlo de algún modo, no ha sido ajeno a críticas y ha generado detractores, quienes han visto esta actividad de la Corte como inconsistente y que, de algún modo, ha creado una situación que, en varios países, implicaría para las autoridades públicas ejercer competencias no previstas constitucionalmente y que, en ciertos casos, podrían derivar en generación de responsabilidad internacional para esos Estados. A continuación, revisaremos las principales críticas de los detractores de esta doctrina.

En primer lugar, quienes consideran a esta doctrina como débil o inconsistente señalan que el artículo 68.1 de la Convención dispone que: "Los Estados Partes en la Convención se comprometen a cumplir la decisión de la Corte en todo caso en que sean partes". Ninguna disposición de este tratado internacional señala que las autoridades nacionales deban acatar la jurisprudencia de la Corte Interamericana en casos en los que no sean Estados partes. Por tanto, en el caso del control de convencionalidad, este tribunal ha emitido lineamientos que deben cumplir los Estados en casos en los que no hayan sido partes, lo cual desnaturalizaría la disposición convencional aquí citada.

Al respecto, el principal argumento en contra de la doctrina del control de convencionalidad proviene del tratadista argentino Ezequiel MALARINO, quien afirma que esta teoría de la Corte, elevada a disposiciones jurisprudenciales, carece de una construcción lógica adecuada, pues establece como premisas lo 
que debería demostrar: la obligatoriedad de su jurisprudencia (MALARINO 425-446). Aún cuando la Corte afirma que los tribunales nacionales deben seguir su jurisprudencia porque es la última intérprete de la Convención y sus fallos son definitivos e inapelables, con arreglo al artículo 67 de la Convención Americana, esto no implica que las autoridades nacionales deban seguir la jurisprudencia de forma obligatoria, ya que la doctrina de un caso no es necesariamente obligatoria para otros casos y otros tribunales. Para esto, se requeriría de una regla adicional en el Sistema Interamericano, la cual no existe. Este autor sostiene que si un tribunal nacional, llámese Corte Suprema o cualquier otro, crea jurisprudencialmente una obligación de seguir las sentencias de la Corte Interamericana, sin fundamento legal o constitucional, violaría el principio de división de poderes. Concluye MALARINO que la Corte confunde no solo el carácter definitivo e inapelable de sus sentencias, con su obligatoriedad respecto a otros casos o tribunales, sino que también confunde quién es la autoridad final para decidir sobre un caso en el Sistema Interamericano y quién lo es en un proceso interno.

El reconocimiento de la competencia contenciosa de la Corte Interamericana por parte de un Estado implica que éste acepta, en el marco de un proceso judicial internacional, que un tribunal conozca sobre un caso en el que se aleguen presuntas violaciones a los derechos consagrados en la Convención Americana cometidas por agentes estatales y, eventualmente, se declare la responsabilidad internacional de dicho Estado; sin embargo, esto es totalmente distinto a que los tribunales internos deban seguir la jurisprudencia de los órganos interamericanos, por lo que MALARINO afirma que no existe conexión entre las premisas y la conclusión. En consecuencia, el argumento de la Corte carece de una construcción lógica adecuada. 
Existe otro sector de la doctrina, crítica de esta teoría del control de convencionalidad, no porque esté en contra de que los jueces y tribunales nacionales controlen que los instrumentos internacionales de derechos humanos no se vean menoscabados por la aplicación de disposiciones de derecho interno contrarias al objeto y fin de dichos tratados (MALARINO tampoco lo está); sino para evitar el surgimiento, afirman, de nuevas tendencias o doctrinas que sean de difícil aplicación práctica o que conlleven, incluso, a un atropellamiento de las competencias que las propias constituciones otorgan a las autoridades locales. Desde esta perspectiva, el autor mexicano Karlos CASTILLA JUÁREZ ha elaborado una importante doctrina crítica del control de convencionalidad, tal cual ha sido concebida por la Corte Interamericana, para que los jueces o tribunales apliquen, dentro de los casos concretos que conocen, el principio pro homine y no una teoría como la expresada, que adolece de inconsistencias lógicas y prácticas (CASTILlA 51-97). Pues bien, revisemos brevemente cuáles son los principales argumentos de este autor para señalar las deficiencias de la doctrina del control de convencionalidad.

Al hablar sobre las características del control de convencionalidad, habíamos mencionado que existen autores que observan cuatro etapas de desarrollo de esta teoría. No obstante, CASTILLA disiente drásticamente de esta apreciación, pues considera que lo que existe es una falta de claridad en la forma de abordar esta teoría, que no se logra apreciar un verdadero desarrollo progresivo y que no define exactamente lo que pretende conseguir; por el contrario, esto revela que existen debilidades estructurales en algo que, incluso, se rehúsa a denominar como doctrina (CASTILLA 60-61). Así, la Corte en el caso Almonacid habla de una "especie" de control de convencionalidad, mientras en el caso Trabajadores 
del Congreso este término ya deja de ser utilizado; es decir, no existe la misma caracterización.

En el caso Gomes Lund, la Corte Interamericana señala que el Poder Judicial está obligado, en el marco del Derecho internacional, a ejercer un control de convencionalidad. No obstante, el autor se pregunta de dónde surge esta obligación, pues ni en la Convención ni en ningún tratado surge tal deber. Es una decisión interna de cada Estado el determinar el lugar, dentro del sistema de fuentes de cada país, que tienen los tratados internacionales (CASTILlA 63). De ahí que se presenten serias dificultades técnicas para implementar esta teoría de la Corte Interamericana, sostiene el doctor CASTILLA. Por ello se pregunta: “¿Con qué legitimidad un tribunal internacional organiza la jerarquía normativa de los Estados?”.

El autor en análisis igualmente considera que es un error asimilar la actividad de la Corte con la de un tribunal constitucional, como lo afirma el ex juez García Ramírez. En efecto, a pesar de las variaciones que pueden existir en los diversos modos de control de constitucionalidad, esencialmente es uniforme, congruente y, por lo general, llevan al mismo fin. En general, la más notable diferencia es el órgano encargado de realizar este control. En cuanto al control de convencionalidad, sólo tiene identidad en las normas de contraste y a contrastar; incluso, esto depende del lugar que los órganos competentes de cada Estado hayan decidido otorgar, dentro del derecho interno, a los tratados internacionales. Por tanto, no existe identidad entre el control concentrado de convencionalidad, a cargo de la Corte Interamericana, y el control difuso de convencionalidad, a cargo de los tribunales internos nacionales (CASTILLA 71-73). 


\section{CONTROL CONCRETO DE CONSTITUCIONALIDAD EN EL ECUADOR}

\section{Sobre el control de constitucionalidad en el Ecuador}

La Constitución de la República del Ecuador establece un modelo concentrado de control constitucional; es decir, está encargado a la Corte Constitucional como único organismo con potestad para destruir la presunción de constitucionalidad de determinados actos de autoridades públicas. En efecto, en lo relacionado con el control abstracto, el artículo 436, en los numerales 2, 3 y 4 de la Constitución, establece expresamente que es competencia de la Corte Constitucional:

1. Conocer y resolver las acciones públicas de inconstitucionalidad, por el fondo o por la forma, contra actos normativos de carácter general emitidos por órganos y autoridades del Estado. La declaratoria de inconstitucionalidad tendrá como efecto la invalidez del acto normativo impugnado.

2. Declarar de oficio la inconstitucionalidad de normas conexas, cuando en los casos sometidos a su conocimiento concluya que una o varias de ellas son contrarias a la Constitución.

3. Conocer y resolver, a petición de parte, la inconstitucionalidad contra los actos administrativos con efectos generales emitidos por toda autoridad pública. Ladeclaratoriade inconstitucionalidadtendrá como efecto la invalidez del acto administrativo.

En el mismo sentido, el artículo 428 de la Norma Fundamental reconoce una competencia adicional, también de control concentrado, pero esta vez concreto: 
Art. 428.- Cuando una jueza o juez, de oficio o a petición de parte, considere que una norma jurídica es contraria a la Constitución o a los instrumentos internacionales de derechos humanos que establezcan derechos más favorables que los reconocidos en la Constitución, suspenderá la tramitación de la causa y remitirá en consulta el expediente a la Corte Constitucional, que en un plazo no mayor a cuarenta y cinco días, resolverá sobre la constitucionalidad de la norma.

Si transcurrido el plazo previsto la Corte no se pronuncia, el perjudicado podrá interponer la acción correspondiente. (El resaltado me corresponde).

Si bien todos estos mecanismos difieren entre sí desde un aspecto procesal, e incluso con relación a los efectos de cada uno, dependiendo de la extensión del control a determinada norma o acto, o su aplicación a un caso concreto, todos parten de una sola reflexión nacida del principio de supremacía constitucional, con la consecuente obligación de establecer mecanismos que controlen la conformidad formal y material del resto del ordenamiento jurídico a sus disposiciones. Para el objeto del presente trabajo, nos interesa enfocarnos en el control concreto de constitucionalidad, consagrado en el artículo 428 de la Constitución del Ecuador.

En aplicación al principio de supremacía constitucional, fuertemente arraigado en el Ecuador desde la promulgación de su Constitución en octubre de 2008, la Norma Suprema establece un sistema de defensa de la Constitución denominado control constitucional, el cual constituye un "conjunto de mecanismos destinados a mantener el funcionamiento del estado dentro de los lineamientos señalados por la voluntad constituyente, y para 
impedir que ese poder exorbitante sea colocado al servicio de intereses diferentes a los de la comunidad" (CHARRY UREÑA 73). Esta defensa de la supremacía constitucional, sin embargo, al igual que el resto de potestades que se ejercen en el contexto de un estado de derecho, está franqueada por límites y limitaciones, que sirven de diques para prevenir un desbordamiento del ciertamente grande poder de los organismos de control constitucional. Sin duda, el principal límite establecido en este sentido está constituido por la denominada "presunción de constitucionalidad". En cuanto se refiere al origen de la presunción de constitucionalidad de la ley, vale la pena mencionar que está aparejada a los propios inicios del control constitucional, en su versión más antigua: el judicial review estadounidense ${ }^{4}$. Fue HAMILTON, quien señaló como función de los tribunales el "declarar nulos los actos contrarios al sentido evidente de la Constitución" (HAMILTON 331). A esta potestad se denominaría "judicial review of legislation", que además de otorgar a los jueces el poder de invalidación de las leyes, les reconoce un poder superior de alteración de las leyes como vía intermedia entre la aceptación del statute y su rechazo.

4 A pesar de que el estadounidense es un sistema de control difuso de constitucionalidad por excelencia, los principios como la presunción de constitucionalidad tienen plena aplicación en el sistema ecuatoriano. En los sistemas concentrados puros, en sus albores, no se concibe un criterio de "presunción de constitucionalidad", sino hasta su "diálogo" con los sistemas concentrados. Esto se puede deber a que el control constitucional establecido por KELSEN no consideraba un examen material de las normas, ya que la propia concepción de "constitución" de KELSEN se refería a las normas que rigen la producción de otras normas. El autor señala: “(...) el hecho que en las decisiones sobre la constitucionalidad de una ley se subsume bajo la norma que representa la Constitución, no es la norma (...), sino la producción de la norma" (KELSEN 109 y ss.). 
Desde esta perspectiva, la presunción de constitucionalidad tomó en cuenta varios aspectos desde su mismo nacimiento. Por una parte, se establece que la labor interpretativa es una forma de poder que caracteriza a los jueces y que, en tanto ejercicio de poder, requiere de límites concretos y objetivos que determinen un adecuado ejercicio de la jurisdicción, de manera que no se limite o interrumpa el poder de otra de las funciones del Estado, encargada constitucionalmente de la elaboración de las leyes. A este respecto, Ricardo GUIBOURG manifiesta que:

la interpretación es el poder que se ignora, el poder que se oculta, el poder del que no se debe hablar. $\mathrm{Su}$ ejercicio es indispensable, pero la luz pública lo debilita. Y aunque todos conocemos desde hace muchos siglos el modo en que funciona, constituye un tema más apropiado para ser tratado en los pasillos que para ser debatido en las salas de audiencias (GUIBOURG 127-128).

Por otra parte, se deja muy en claro el respeto casi absoluto e irrestricto por la legitimidad democrática del trabajo del legislador, quien en principio ejerce su libertad configurativa, en cuanto a la creación de leyes, sin exceder sus limitaciones impuestas constitucionalmente. Claro que esta afirmación solo puede ser llevada adelante si consideramos los momentos históricos en que esos fallos de la justicia norteamericana, antes anotados, fueron emitidos, generalmente en un momento histórico constitucional totalmente distinto al actual, ya que desde el siglo XIX se tiende a la inserción de una mayor cantidad de derechos sociales en las constituciones que establecen una carga prestacional para el Estado. Por consiguiente, la producción legislativa va a tomar comoreferencia esa serie de derechos novedosos que se encuentran 
ávidos de protección y jurisdiccionalidad y, por lo mismo, el sujeto jurisdiscente se ve abocado a la imperiosa obligación de hacer que la Norma Normarum no tienda a petrificarse, dejando de lado aquel viejo principio formulado por MONTESQUIEU de que el "el juez es la boca de la ley".

En el caso ecuatoriano, el principio de presunción de constitucionalidad está manifiestamente considerado en la Ley Orgánica de Garantías Jurisdiccionales y Control Constitucional (en adelante "LOGJCC"), cuando dispone lo siguiente:

Art. 76.- Principios y reglas generales.- El control abstracto de constitucionalidad se regirá por los principios generalesdelcontrolconstitucionalprevistos por la Constitución y las normas constitucionales, la jurisprudencia y la doctrina. En particular, se regirá por los siguientes principios:

(...)

2. Presuncióndeconstitucionalidaddelasdisposiciones jurídicas.- Se presume la constitucionalidad de las disposiciones jurídicas.

\section{Naturaleza jurídica del control concreto de constitucionalidad}

El control concreto de constitucionalidad en el Ecuador encuentra su fundamento en el citado artículo 428 de la Constitución de la República (en adelante "Constitución", "Norma Suprema" o "Carta Magna"). Este mecanismo es desarrollado por la LOGJCC, en su artículo 141, que dispone: 
Artículo 141.- Finalidad y objeto el control concreto de constitucionalidad.- El control concreto tiene como finalidad garantizar la constitucionalidad de la aplicación de las disposiciones jurídicas, dentro de los procesos judiciales.

Losjuecesaplicarán las disposiciones constitucionales, sin necesidad de que se encuentren desarrolladas en otras normas de menor jerarquía.

En las decisiones no se podrá restringir, menoscabar o inobservar su contenido.

El siguiente artículo de este cuerpo legal dispone que el control concreto de constitucionalidad procede de dos maneras: de oficio, es decir, por solicitud expresa y directa de los administradores de justicia; y a petición de la o las partes procesales de una contienda judicial. ${ }^{5}$ Sin embargo, para que la Corte Constitucional del

Ver Art. 142 de la LOGJCC, Procedimiento.- Las juezas y jueces, las autoridades administrativas y servidoras y servidores de la Función Judicial aplicarán las disposiciones constitucionales, sin necesidad que se encuentren desarrolladas en otras normas de menor jerarquía. En las decisiones no se podrá restringir, menoscabar o inobservar su contenido.

En consecuencia, cualquier jueza o juez, de oficio o a petición de parte, solo si tiene duda razonable y motivada de que una norma jurídica es contraria a la Constitución o a los instrumentos internacionales de derechos humanos, que establezcan derechos más favorables que los reconocidos en la Constitución, suspenderá la tramitación de la causa y remitirá en consulta el expediente a la Corte Constitucional, la que en un plazo no mayor a cuarenta y cinco días resolverá sobre la constitucionalidad de la norma.

Si transcurrido el plazo previsto la Corte Constitucional no se pronuncia, el proceso seguirá sustanciándose. Si la Corte Constitucional resolviere luego de dicho plazo, la resolución no tendrá efecto retroactivo, pero quedará a salvo la acción extraordinaria de protección por parte de quien hubiere sido perjudicado por recibir un fallo o resolución contraria a la resolución de la 
Ecuador proceda a realizar el control de constitucionalidad, el juez debe tener una duda razonable y motivada de que la norma en cuestión es contraria a la Constitución o a los tratados internacionales de derechos humanos que establezcan derechos más favorables que los reconocidos en la Constitución.

\section{Al respecto, la Primera Corte Constitucional del Ecuador ha señalado que:}

(...) la consulta de constitucionalidad no puede tornarse en un mecanismo de dilación de la justicia y vía de escape de las juezas y jueces del país (...) la consulta debería proceder única y exclusivamente cuando existe una motivación razonada de por qué acude a la consulta, pues, un proceder contrario deviene en jueces pasivos, no comprometidos con la protección de derechos, ya que estos se desatienden de la resolución de la causa sin un legítimo motivo constitucional. (...) Así pues el concepto de duda razonable (...) no puede ser entendido de manera independiente al concepto de motivación (...) Las juezas y jueces constitucionales tienen la obligación de advertir y fundamentar ante la Corte Constitucional, la existencia de disposiciones normativas contrarias a la Constitución (...)” (Corte Constitucional del Ecuador, 2013).

Corte Constitucional.

No se suspenderá la tramitación de la causa, si la norma jurídica impugnada por la jueza o juez es resuelta en sentencia.

El tiempo de suspensión de la causa no se computará para efectos de la prescripción de la acción o del proceso. 
Adicionalmente, la Corte Constitucional concluye que

(...) la consulta de norma no puede tener como único fundamento la opinión de una de las partes sobre la constitucionalidad de la norma jurídica, sino la coherente y exhaustiva exposición de las razones que llevan al juez o jueza a no encontrar una interpretación de la norma o su aplicación al caso que sea compatible con la Constitución; es decir, la consulta debe ser adecuadamente motivada (Corte Constitucional del Ecuador 2013a).

En este contexto, la Corte ha precisado que para que una consulta de norma dentro del control concreto de constitucionalidad pueda considerarse adecuadamente motivada, deberá contener al menos los siguientes presupuestos (Corte Constitucional del Ecuador 2013b):

1. Identificación del enunciado normativo cuya, constitucionalidad se consulta, obligación que está a cargo de los jueces y juezas para denotar la relevancia constitucional.

2. Identificación de los principios o reglas constitucionales que se presumen infringidos, exponiendo motivadamente las circunstancias y razones por las cuales dichos enunciados son determinantes en el proceso.

3. Explicación y fundamentación de la relevancia de la norma puesta en duda, respecto de la decisión de un caso concreto, indicando las razones por las cuales el precepto normativo es indispensable para decidir sobre el fondo de la cuestión. 
En este caso, los jueces tienen la obligación de suspender la tramitación de la causa y remitir en consulta el expediente del proceso que contenga la disposición normativa presuntamente contraria a la Constitución. Finalmente, conviene mencionar que la sentencia que dicte la Corte Constitucional tiene o puede tener dos efectos:

1. Erga omnes, en aquellos casos en los cuales la Corte se pronuncie respecto de la compatibilidad de la disposición jurídica en cuestión, con las normas constitucionales.

2. Interpartes, en los casos en que la Corte se pronuncia únicamente sobre la constitucionalidad de la aplicación de la norma jurídica. 


\section{EL CONTROL DE CONVENCIONALIDAD DESDE LA PERSPECTIVA CONSTITUCIONAL ECUATORIANA}

Una vez que hemos analizado el control de convencionalidad y el control concreto de constitucionalidad, conviene revisar si estos dos mecanismos pueden converger y reforzarse entre sí, y en qué forma; igualmente, si existe un diálogo entre el Derecho constitucional y el Derecho internacional y, de ser así, cómo se produce. En el caso ecuatoriano, es necesario determinar las posibilidades reales de esta comunicación y si es posible ejercer el control de convencionalidad por parte de los jueces, con el fin de lograr una mayor protección de la persona humana en nuestro sistema constitucional. Por tal motivo, en esta última sección abordaremos la forma en que el Derecho internacional se incorpora al derecho interno, si en realidad los jueces ecuatorianos pueden y deben realizar el control de convencionalidad, en los términos descritos en esta investigación, a la luz de las normas constitucionales ecuatorianas, y cómo los jueces deben o deberían realizar dicho control.

Debido al fenómeno denominado internacionalización del Derecho constitucional y constitucionalización del Derecho internacional de los derechos humanos, que consiste en que el derecho se nutre de la correlación entre el Derecho constitucional y el Derecho internacional de los derechos humanos (AYALA CORAO 20), los tribunales internacionales y nacionales realizan lo que la doctrina ha señalado como diálogo jurisprudencial, por medio del cual las jurisdicciones nacionales deben considerar los fallos e interpretaciones efectuadas por los tribunales internacionales $\mathrm{y}$, a su vez, estos deben tener presentes las observaciones que realicen los tribunales internos con respecto a los criterios del tribunal internacional (BAZÁN). En este sentido, se debe procurar 
cierta coherencia de la jurisprudencia para evitar contradicciones, de manera que se alcancen interpretaciones convergentes (GARCÍA ROCA 39). En particular, esta tarea la deben realizar los tribunales constitucionales o salas de corte suprema, según el sistema adoptado por cada país. Por tanto, no es extraño que los tribunales o cortes constitucionales latinoamericanas sean los principales interlocutores con la Corte Interamericana, dado el carácter de intérprete máximo de ambas jurisdicciones en materia de derechos y, además, porque los primeros deben aplicar, explicar y divulgar la jurisprudencia internacional sobre derechos humanos en su respectiva jurisdicción (GARCÍA ROCA 44). En especial, esto ha sido posible gracias a la incorporación de los derechos consagrados en la Convención Americana al denominado bloque de constitucionalidad, de manera que los tribunales o cortes constitucionales han podido o podrían aplicar directamente los derechos consagrados en dicho tratado, conjuntamente con la interpretación dada por la Corte Interamericana o los derechos constitucionales, con arreglo a la interpretación jurisprudencial de dicho tribunal internacional (AYALA CORAO 90).

Este fenómeno jurídico no es ajeno a la realidad constitucional del Ecuador, a raíz de la vanguardista Constitución de 2008. En efecto, la Norma Suprema incorpora a los tratados internacionales en materia de derechos humanos dentro del bloque de constitucionalidad y les otorga rango constitucional, siempre que reconozcan derechos más favorables que aquellos consagrados en la Constitución ${ }^{6}$. Tal situación es determinante para establecer

6 Ver Constitución de la República del Ecuador, Art. 424.- La Constitución es la norma suprema y prevalece sobre cualquier otra del ordenamiento jurídico. Las normas y los actos del poder público deberán mantener conformidad con las disposiciones constitucionales; en caso contrario carecerán de eficacia jurídica. 
la jerarquía normativa de los tratados internacionales en esta materia, es decir, su relevancia dentro del sistema de fuentes nacional.

Sobre este tema, la Corte Constitucional sí ha recurrido a la doctrina del control de convencionalidad, cuando ha visto necesario hacerlo, en su criterio, con el fin de precautelar los derechos constitucionales de mejor manera. No es el objetivo de este trabajo realizar una crítica a la utilización correcta o incorrecta de esta herramienta jurídica por parte de la Corte Constitucional, lo cual implicaría analizar cada sentencia en la cual la Corte ha empleado esta doctrina en su argumentación jurídica; sino que es el interés de esta investigación, indicar al lector que en ocasiones el máximo órgano de administración de justicia constitucional en el Ecuador ha recurrido a este recurso jurídico en su fundamentación. En este orden de ideas, la Corte Constitucional ecuatoriana ha señalado que:

En consecuencia, para garantizar de mejor forma los derechos constitucionales, el control de constitucionalidad no debe ser visto como el único mecanismo a ser implementado por la Corte sino que además se debe tener en cuenta la existencia del control de convencionalidad como el mecanismo por medio del cual los jueces nacionales pueden efectuar el análisis de una norma, tornando en consideración la Convención Americana de Derechos

La Constitución y los tratados internacionales de derechos humanos ratificados por el Estado que reconozcan derechos más favorables a los contenidos en la Constitución prevalecerán sobre cualquier otra norma jurídica o acto del poder público. 
Humanos, las sentencias que dotan de contenido a la Convención emitidas por la Corte Interamericana de Derechos Humanos y todos aquellos instrumentos internacionales de derechos humanos ratificados por el Ecuador, en suma, aquello que se denomina el ius comune interamericano (Corte Constitucional del Ecuador 2014).

Pues bien, en cuanto al control de convencionalidad que realizan los jueces o deben realizar, de conformidad a los parámetros que se indicaron en el primer acápite de este artículo, y al contrastar con las normas que regulan el denominado control concreto de constitucionalidad, analizado precedentemente, encontramos que es a través de este mecanismo que los jueces ecuatorianos y la Corte Constitucional del Ecuador pueden realizar el control de convencionalidad. Como quedó dicho en al acápite anterior, el artículo 428 de la Constitución ecuatoriana regula este mecanismo que busca adecuar las normas infraconstitucionales con el texto de la Norma Suprema. Sin embargo, establece una clara limitación con respecto a los tratados internacionales, pues este control sólo se puede ejercer, con respecto al derecho internacional de los derechos humanos, cuando existan derechos reconocidos en dichos tratados que sean más favorables a aquellos que la Constitución ecuatoriana reconoce. En definitiva, al contrastar una norma jurídica interna con el tratado internacional de derechos humanos, el juez debe determinar si éste reconoce un derecho que favorezca de mejor manera a la persona humana que aquellos consagrados en la Constitución; de ser así, podría entonces esta norma ser inconstitucional, si así lo declara la Corte Constitucional, como organismo de máxima interpretación constitucional en el Ecuador, a la luz del Derecho internacional de los derechos humanos. 
El juez, al realizar el análisis en mención, debe guiarse por los principios pro homine, de progresividad y de supremacía de la Constitución. Por ello, en primer lugar, el juez requiere determinar si el derecho en cuestión está mejor protegido en el tratado internacional que en la Constitución ecuatoriana; debe identificar la jurisprudencia interamericana relevante para el caso concreto; y, si encuentra que ese derecho está mejor protegido en el tratado internacional, de tal manera que le lleva a dudar razonablemente de la constitucionalidad de la norma, debe remitir en consulta el caso a la Corte Constitucional. Este organismo deberá analizar el caso tomando en particular consideración a la jurisprudencia de la Corte Interamericana, siempre en procura de una mejor protección de la persona humana.

\section{CONCLUSIONES}

El control de convencionalidad, figura jurídica creada por la Corte Interamericana de Derechos Humanos, a pesar de sus críticas y potenciales inconsistencias, puede constituir un interesante mecanismo de protección de derechos humanos. No era la pretensión del trabajo que pongo a vuestra consideración, el realizar críticas específicas a este control, sino encontrar un procedimiento que permita a los operadores de justicia constitucional en el Ecuador realizar dicho control con arreglo a las disposiciones constitucionales y legales vigentes en nuestro país. En otras palabras, que en sus decisiones y argumentación jurídica, cuando traten cuestiones relativas a derechos constitucionales, tengan presente los tratados internacionales sobre derechos humanos que el Ecuador ha ratificado, en el marco del Sistema Interamericano, con el fin de que sus decisiones se ajusten a la Convención Americana sobre Derechos Humanos y la interpretación que de ella ha efectuado el Tribunal Interamericano. 
Los administradores de justicia constitucional, cuando resuelvan las causas en su conocimiento, no solo deben tener en cuenta la legislación ecuatoriana interna y la jurisprudencia de los tribunales nacionales, sino también deben prestar particular atención a la jurisprudencia de la Corte Interamericana de Derechos Humanos, en lo que al caso bajo su análisis se refiere. En este trabajo propongo que, al realizar este control de convencionalidad, si los jueces tienen una duda razonable acerca de que una norma jurídica interna, es incompatible con la Convención Americana, siempre que este instrumento internacional contenga derechos más favorables para el ser humano, deberán remitir la causa en consulta a la Corte Constitucional, de conformidad con los criterios vertidos en esta investigación. Finalmente, al momento de decidir, esta Corte deberá considerar la interpretación que ha realizado la Corte Interamericana en su jurisprudencia sobre el asunto en cuestión y, de este modo, arribar a una resolución que proteja de mejor manera los derechos humanos. 


\section{BIBLIOGRAFÍA}

AYAla CORAO, Carlos. Del diálogo jurisprudencial al Control de Convencionalidad. Colección de Estudios Jurídicos N. ${ }^{\circ}$ 98, Caracas: Editorial Jurídica Venezolana, 2012.

BAZÁN, Víctor. El control de convencionalidad: incógnitas, desafios y perspectivas. 2012a, disponible en http:// www.corteidh.or.cr/tablas/r30034.pdf.

."Estimulando sinergias: de diálogos jurisdiccionales y controldeconvencionalidad", en FERRER MAC-GREGOR, Eduardo (coord.), El control difuso de convencionalidad. Diálogo entre la Corte Interamericana de Derechos Humanos y los jueces nacionales, . Querétaro: Fundap, 2012b.

CANÇADO TRINDADE, Antônio. "Derecho Internacional de los Derechos Humanos, Derecho Internacional de los Refugiados y Derecho Internacional Humanitario: aproximaciones y convergencias", en BUERGENTHAL, Thomas y CANÇADO TRINDADE, Antônio A. (compiladores), Estudios Especializados de Derechos Humanos, 1. a ed., San José, Costa Rica: IIDH, 1996.

CARBOnEll, Miguel. "Introducción General al Control de Convencionalidad", en Biblioteca Jurídica Virtual del Instituto de Investigaciones Jurídicas de la UNAM. Disponible en http://biblio.juridicas.unam.mx/ libros/7/3271/11.pdf. 
CAstilla JuÁrez, Karlos A. “Control interno o difuso de convencionalidad? Una mejor idea: la garantía de tratados", en Anuario Mexicano de Derecho Internacional, vol. XIII. México DF: Universidad Nacional Autónoma de México-Instituto de Investigaciones Jurídicas, 2013.

CHARRY UREÑA, J. Justicia constitucional, Derecho comparado y colombiano, Bogotá: Banco de la República, 1993.

COMITÉ de Derechos Económicos, Sociales y Culturales. Observación General N. ${ }^{\circ} 13,21 .^{\circ}$ período de sesiones, 1999, HRI/GEN/1/Rev. 5.

FERRER, Eduardo. "Interpretación conforme y control difuso de convencionalidad. El nuevo paradigma para el juez mexicano", en CARBONELL, Miguel y SALAZAR, Pedro (coords.), La reforma constitucional en materia de derechos humanos: un nuevo paradigma, México: Porrúa-UNAM, 2012.

GARCÍA ROCA, Xavier. "El diálogo entre el Tribunal Europeo de Derechos Humanos y los tribunales constitucionales en la construcción de un orden público europeo", en Teoría y realidad constitucional, N. ${ }^{\circ}$ 30, Madrid: sd, 2012.

GUIBOURG, Ricardo. Deber y saber. Apuntes epistemológicos para el análisis del derecho y la moral. México DF: Fontamara, 1997.

HAMILTON, MADISON y JAY. El federalista, México: Fondo de Cultura Económica, 2000. 
KELSEN, Hans. "La Garantía Jurisdiccional de la Constitución - La Justicia Constitucional", en MANERO, Juan Luis. (trad.), Escritos sobre la Democracia y el Socialismo, . Madrid: Debate, 1988.

MALARINO, Ezequiel. "Acerca de la pretendida obligatoriedad de la jurisprudencia de los órganos interamericanos de protección de derechos humanos para los tribunales judiciales nacionales", en ELSNER Gisela, KAI Ambos, MALARINO Ezequiel (coords.), Sistema interamericano de protección de los derechos humanos y derecho penal internacional, sd, 2010.

\section{CUERPOS NORMATIVOS}

- Convención Americana sobre Derechos Humanos.

- Pacto Internacional de Derechos Civiles y Políticos.

- Pacto Internacional de Derechos Económicos, Sociales y Culturales.

- Convención de Viena sobre el Derecho de los Tratados.

- Convención de Naciones Unidas sobre los Derechos del Niño.

- Convención Europea sobre Derechos Humanos.

- Constitución de la República del Ecuador.

- Ley Orgánica de Garantías Jurisdiccionales y Control Constitucional.

\section{JURISPRUDENCIA}

- Corte Interamericana de Derechos Humanos, La expresión leyes en el artículo 30 de la Convención 
Americana sobre Derechos Humanos, opinión consultiva OC-6/86, de 9 de mayo de 1986, Serie A, N. 6.

- Corte IDH, caso Velásquez Rodríguez vs. Honduras, sentencia de 29 de julio de 1988, Serie C, N. ${ }^{\circ} 14$.

- Corte IDH, caso La Cantuta vs. Perú, sentencia de 29 de noviembre de 2006a (Fondo, Reparaciones y Costas), Serie C, N. ${ }^{\circ} 162$.

- Corte IDH, caso Instituto de Reeducación del Menor vs. Paraguay, sentencia de 2 de septiembre de 2004a, Serie C, N. ${ }^{\circ} 112$.

- Corte IDH, caso Myrna Mack Chang vs. Guatemala, sentencia de 25 de noviembre de 2003 (Fondo, reparaciones y costas), Serie C, N. ${ }^{\circ} 101$.

- Corte IDH, caso Tibi vs. Ecuador, sentencia del 7 de septiembre de 2004b (Excepciones preliminares, fondo, reparaciones y costas), Serie C, N. ${ }^{\circ} 114$.

- Corte IDH, caso Almonacid Arellano y otros vs. Chile, sentencia de 26 de septiembre de 2006b (Excepciones preliminares, fondo, reparaciones y costas), Serie C, N. ${ }^{\circ} 154$.

- Corte IDH, caso Trabajadores Cesados del Congreso (Aguado Alfaro y otros) vs. Perú, sentencia de 24 de noviembre de 2006c (Excepciones preliminares, fondo, reparaciones y costas), Serie C, N. ${ }^{\circ} 158$.

- Corte IDH, caso La Cantuta vs. Perú, sentencia de 29 de noviembre de 2006 (Fondo, reparaciones y costas), Serie C, N. ${ }^{\circ} 162$.

- CorteIDH, caso Heliodoro Portugal vs. Panamá, sentencia de 12 de agosto de 2008 (Excepciones preliminares, fondo, reparaciones y costas), Serie C, N. ${ }^{\circ} 186$.

- Corte IDH, caso Boyce y otros vs. Barbados, sentencia de 20 de noviembre de 2007 (Excepción preliminar, fondo, reparaciones y costas), Serie C, N. ${ }^{\circ} 169$. 
- Corte IDH, caso Radilla Pacheco vs. México, sentencia de 23 de noviembre de 2009 (Excepciones preliminares, fondo, reparaciones y costas), Serie C, N. 209.

- Corte IDH, caso Cabrera García y Montiel Flores vs. México, sentencia de 26 de noviembre de 2010 (Excepción preliminar, fondo, reparaciones y costas, Serie C, N. ${ }^{\circ} 220$.

- Corte IDH, caso Gelman vs. Uruguay, sentencia de 24 de febrero de 2011 (Fondo y reparaciones), Serie C, N. 221.

- Corte IDH, opinión consultiva OC-4/84 de 19 de enero de 1984, Propuesta de modificación a la Constitución Política de Costa Rica relacionada con la naturalización, Serie A, N. ${ }^{\circ} 4$.

- Corte IDH, caso "La Última Tentación de Cristo" (Olmedo Bustos y otros) vs. Chile, sentencia de 5 de febrero de 2001 (Fondo, reparaciones y costas), Serie C, N. 73.

- Corte Internacional de Justicia, "Case Concerning Military and Paramilitary Activities In and Against Nicaragua (Nicaragua vs. United States of America). Jurisdiction of the Court and Admissibility of the Application. Judgment", 26 de noviembre de 1984, en Yearbook of the International Court of Justice, Países Bajos, La Haya.

- CorteConstitucional delEcuador.Sentencia030-13-SCNCC, caso 0697-12-CN, petición de consulta de norma efectuada por la Corte Nacional de Justicia; y Sentencia 036-13-SCN-CC, caso 0047-11-CN, petición de consulta de norma efectuada por el Juez de lo Civil de Pastaza, de 14 de mayo de 2013.

- CorteConstitucional delEcuador.Sentencia014-13-SCNCC, publicada en el Registro Oficial Tercer Suplemento N. ${ }^{\circ}$ 932, de 12 abril de 2013a. 
- CorteConstitucionaldelEcuador. Sentencia001-13-SCNCC, caso 0535-12-CN (Jueces del Tribunal Distrital de lo Contencioso Administrativo N. ${ }^{\circ}$ 3, con sede en Cuenca), publicada en el Registro Oficial Segundo Suplemento N. ${ }^{\circ} 890$, de 13 de febrero de 2013b.

- Corte Constitucional del Ecuador. Sentencia N 003-14SN CC, de 17 de septiembre de 2014. 